\title{
Merger Repair: A Conceptual Framework for Restoring Employer/Employee Relationships
}

\author{
Timothy Galpin \\ J. Lee Whittington \\ University of Dallas
}

\begin{abstract}
During mergers and acquisitions a variety of integration management transgressions both intentional and unintentional - occur. If these are not addressed, there will be a severe and potentially permanent damage to the relationship between the organization and its employees. This area of study has been identified as lacking sufficient examination and is ripe for future work (Haleblian, Devers, McNamara, Carpenter, \& Davison, 2009). In this paper, we identify the common sources of these integration transgressions. Drawing on research based in social psychology and merger integration, we develop the construct of merger repair. We also identify several techniques for repairing the damaged relationships. Implications for practitioners and propositions to guide future research are developed.
\end{abstract}

Every corporate acquisition or merger begins with high expectations. Those in favor of the deal -typically, senior management - routinely project synergies to be achieved which will produce levels of performance that have never been achieved. However, this is an often naïve view held by decision makers about a potential deal and the majority of $M \& A$ transactions fail to meet those lofty expectations. Moreover, because management is often out of touch with rank-and-file's typically lower expectations pertaining to a pending merger or acquisition, management's confidence about the ease of synergy achievement is frequently unrealistic.

We don't have to look far to find examples of failed mergers and acquisitions. The illfated 1998 acquisition of Chrysler by Daimler, was based on the promise of the Daimler CEO that the acquisition would result in "an historic merger of mass with class" (Edmondson, Welch, Thornton, \& Palmer, 2005, pp.1). Together, these giants of the automotive industry would have the money, clout, and know-how needed to produce next-generation engine technologies. They would produce a series of small cars for the world's emerging middle classes. Chrysler would tap into Mercedes technology, and Chrysler would give Mercedes the ideal hedge in case the luxury car market plateaued. Synergies and cost savings would proliferate. Nothing worked out as planned. (Edmondson, et al., 2005).

Similarly, the combination of Sprint and Nextel, to form the third largest US wireless carrier, went through a poorly executed integration process. Taylor (2006) comments about the Sprint/Nextel merger, "The departure of Sprint Nextel's chief operating officer...comes amid problems of customer churn and disappointing results that are 
seen by analysts as symptomatic of problems with integrating the merger that created the company"(pp. 1). Likewise, regarding the troubled merger of Time Warner and AOL, Joyce (2003) notes, "It's official, AOL is off the corporate nameplate of the world's largest media company. But, Time Warner executives stressed their commitment to the corporate marriage of $\mathrm{AOL}$ and Time Warner - despite three turbulent years that followed the once-ballyhooed merger" (pp. 1).

In another examination of a failed transaction, Calandro (2008) applies Bruner's (2005) disaster analysis framework to the 1998 acquisition of the General Reinsurance Corporation (Gen Re) by Warren Buffet's Berkshire Hathaway. Calandro notes that, "The business press has extensively reported on Buffett's acquisitions, including a number of notable successes...Buffett has not, however, been immune to the occasional 'Deal from Hell.' One such deal was the 1998 acquisition of the General Reinsurance Corporation" (p. 21). Bruner's framework is comprised of six dimensions: Complexity - an aspect of the business or deal that makes it difficult to understand and/or value; Tight coupling - limited or no flexibility to absorb miscalculations about the value of an acquisition; Business not as usual - turmoil in the economic environment that produces or contributes to errors; Cognitive biases - for example, over-confidence; Adverse management choices - decisions that increase the risk of a deal; and Operational team flaws - cultural differences, lack of candor, political infighting, and/or inconsistent leadership. Calandro's discussion illustrates that on all six dimensions of Bruner's framework Berkshire Hathaway made serious mistakes which ultimately caused deal performance to suffer, with the company losing money for four straight years following the acquisition.

Likewise, Guerrera (2009) assesses the integration of the $\$ 83$ billion merger of Citicorp and Travelers to form Citigroup in 1998 by noting that "A decade later, the dream of an all-purpose global financial conglomerate capable of selling insurance to New Jersey housewives and stocks to Thai investors lies in tatters... weakened by years of infighting (and) poor management...the original sin of Citi's conception was that its diverse businesses were not properly integrated" (pp. 1). Unfortunately, the errors of Citicorp's management may be doomed to be repeated.

A common element across these and other failed deals is the importance of the integration effort on deal performance (Galpin and Herndon, 2007). The success or failure of merger integration efforts depends in large part on the level of trust that employees extend toward their leaders, and trust is at least partially based on perceived competence. Thus, errors in judgment or faulty assumptions about the efficacy of a transaction on management's part can damage that trust. Moreover, due to the phenomenon of groupthink (Janis, 1982), it is often easier for others in an organization to identify another's incompetence during M\&A integration than for the person or group to identify their own incompetence. Therefore, the gap between the perspectives of management and employees about the how an integration effort is being managed may well contribute to a deterioration of employee trust in management. To the employees, who are often the most familiar with management's decisions, errors in management's assumptions and decisions during integration are excruciatingly obvious. This may lead 
to many forms of resistance which can significantly contribute to poor integration and negative transaction performance.

Cases such as the ones discussed above are sensational and garner a great deal of public attention. Yet, smaller firms are not exempt from these problems. It is easy to assume that the managers of smaller firms with flatter structures would be more in touch with their employees' expectations about pending mergers and acquisitions, minimizing employer/employee relationship issues such as trust and cooperation. However, this does not seem to be the case. Although the extant empirical literature regarding the dynamics of $M \& A$ integration and employer/employee relationships does not differentiate between large and small firm M\&As, some case evidence suggests that the organizational dynamics of small firm transactions mirror those of large firm M\&As. For example, poor M\&A performance due to inadequate M\&A planning and integration management has been documented for small- to mid-size industry consolidations including freight hauling (Prince, 2009), cleaning services, garden supplies, lawn services, (Gilbert, 1989), and scrap metal (Marley, 2008).

Regardless of firm size, it appears that a majority of firms encounter significant M\&A performance issues. Beyond the evidence of highly public cases, a strong base of empirical research overwhelmingly supports the notion that most mergers and acquisitions (M\&As) fail to live up to performance expectations. In general, M\&As do not improve acquiring firm value, as measured by either short-term or long-term performance measures. In fact, M\&As are frequently erode the value of the acquiring firm (Agrawal \& Jaffe, 2000; Haleblian, Devers, McNamara, Carpenter, \& Davison, 2009; LaJoux \& Weston, 1998). Carow, Heron, and Saxton (2004) investigated the impact of acquisition activities on the financial performance of the acquiring firm. They concluded that on average the financial return on these activities was negative. Marks and Mirvis (2001) examined seventy mergers and acquisitions and concluded that three out of four failed to achieve their financial and strategic objectives. The cost of failed mergers and acquisitions extends beyond financial outcomes. These failures impact other stakeholders - employees, customers, and suppliers - as well (Haleblian et al., 2009).

In view of the high M\&A failure rate, a reasonable question to pose is "Why do M\&As continue to be so popular with management?" The reasons for this might vary. One explanation may be bounded rationality, which argues that management decisions are often based on good intentions, but that the ability of management to gather, comprehend, and retrieve information and then make inferences is limited. This tendency is exacerbated by many factors. First, the environments in which their companies operate are exceedingly complex. Second, management's mental capabilities are limited in comparison with the demands of an extremely complex environment. Third, executives are constrained from attempting to fully understand environmental complexities by finite resources such as available time, staff, and capital. As a result of these limitations, managers often make decisions under conditions of uncertainty (Ibrahim, 2009). 
Another key reason that M\&As continue to be popular among management may be explained by reinforcement theory, which proposes that individuals' behaviors are shaped by consequences, i.e. the presence of rewards and the absence of punishments. These consequences create the likelihood that individuals will repeat or terminate a given behavior. Reinforcement theory is essentially a theory of learning, in that when an individual is rewarded for having engaged in a behavior, he or she is more likely to do so again. Similarly, individuals are less likely to engage in a behavior when they learn that punishments will follow (Michener \& DeLameter, 1999; Skinner, 1953).

The recent bank bailouts may be interpreted as reinforcement for decisions - even poor decisions and mismanagement on the part of Citigroup's executives. Thus, management at Citicorp (and other similar institutions) may tend to become even more certain that their assumptions about the value of M\&A activity are correct. If this is the case, then the management of Citicorp's grasp of actual firm performance versus their reinforced beliefs about what is rewarded may grow further apart rather than closer together.

Yet another explanation may be self-serving behavior (e.g. personal wealth creation) on the part of the management team that makes up the organization's dominant coalition. A dominant coalition consists of the network of individuals within and around an organization that most influence the mission and goals of the organization (Cyert \& March, 1963). This coalition also controls significant organizational resources enables management to maneuver the organization to achieve their individual or group goals rather than the broader organizational goals (Pfeffer \& Salancik, 1978). Some of the resources that are often under management's overriding control are access to physical resources, capital, or specific knowledge (Burt, 1992).

Still another explanation for M\&A popularity may be herd theory. Economists have applied herd theory to explain the behavior of investment managers in the financial market place. The theory contends that investment managers often follow the decisions of other managers and that they will ignore their own other contrary information when making decisions about stocks and mutual funds (Nofsinger \& Sias, 1999; Scharfstein \& Stein, 1990). Investment managers see what their peers are doing and once the first manager acts, the others quickly follow (Banerjee, 1992). Although such actions may appear to be poor decisions, they are justified by the perception that it is better to go with the herd than risk failure by going it alone. Managers find not only safety in numbers, but there is also a psychological reinforcement as well (Hunter, 2002). The fundamentals of herd theory can clearly be extended to executives who seemingly make poor choices regarding the value of pursuing mergers or acquisitions because they are following the herd. Once one company in an industry moves forward with a merger or acquisition, it is often the case that other management teams in the same industry seem to quickly follow.

\section{The Causes of M\&A Failures}

M\&A failures have been attributed to a variety of causes. Datta (1991) examined 173 acquisitions and concluded that differences in the styles of top management teams 
were a primary contributor to negative post-acquisition performance. These differences in management style also impacted post-acquisition integration efforts. Pablo (1994) identifies the need to examine the integration issues facing combining organizations through multiple perspectives. The financial, strategic, structural, human resource, and cultural perspectives must each be given full attention. Larson and Finkelstein (1999) cite the lack of understanding of the complexity involved in integrating organizations. They call for a more comprehensive perspective that integrates both macro issues such as strategy and structure along with the micro-oriented human resource issues. Marks and Mirvis (2001) found that inadequate "pre-combination" management designed to address the strategic and psychological factors of the integration are a principal cause of underperformance. Another reason for failure of mergers was the incompatibility of the cultures of the organizations. These cultural incompatibilities create tension, inefficiency, and poor performance (Cameron, Quinn, DeGraff, \& Thakor, 2006).

Despite the clear need for more comprehensive merger integration planning, common management transgressions persist. These transgressions may be intentional; however, even unintended transgressions can have a severe impact on the success of integration efforts. This is often the result of failing to create a clear and comprehensive approach to managing the integration before the integration begins. With this in mind, pretransaction due diligence should be conducted pertaining not only to the traditional financial, legal, technical, environment, and operational fit of the firms, but also with regard to the non-traditional organizational characteristics of the target firm such as culture and human resources (Atkinson, \& Clarke, 2007; Fisher, 2004). Despite the obvious importance of these factors, cultural fit is often downplayed or ignored during due diligence (Galpin \& Herndon, 2007). In a study of 40 acquisitions, Marks (1999) found that all companies conducted a detailed financial and legal audit of their intended target. However, none of the companies assessed their target's human resources to evaluate the talent they were acquiring or to identify cultural norms. The lack of cultural due diligence in most transactions may be due to management becoming captivated with the strategic fit presented by a potential combination. The lack of focus on these "softer" dimensions may also be due to an underestimation of culture's impact on integration efforts by management (Schweiger \& Goulet, 2000). The failure to recognize and plan for dealing with differences in management philosophy and organizational cultures hinders the implementation of necessary organizational changes. The lack of an integration plan also results in slow decision-making and poor communications. Employees in the acquired firm feel like second-class citizens (Galpin and Herndon, 2007) and these unresolved differences fuel the lack of trust in management and the conflict between employees of the combined firm. Furthermore, commitment to the newly formed organization is slow to develop (Schweiger \& DeNisi, 1991; Ulrich, Cody, LaFasto, \& Rucci, 1989).

When these problems manifest themselves, managerial attention is devoted to these issues and the critical task of identifying and retaining key talent gets lost in the shuffle. Employees may perceive the human side of the integration process as unfair and their commitment - if, in fact it existed - to the new organization begins to wane (Klendauer \& Deller, 2009). Poor integration management exacerbates the stress employees 
experience and voluntary turnover increases (Brahma \& Kaillash, 2007). As a result, in the midst of the integration, those employees who can leave, leave (Bedeian \& Armenakis, 1998). Moreover, as people across the company leave, especially those whose skills are most saleable in the job market, firms experience significant drops in organization-wide productivity (Galpin \& Herndon, 2007; Bedeian \& Armenakis, 1998). Thus, those whose skill sets may have been most important to the integration effort leave. This exodus further impacts the already declining productivity of the organization and hampers the integration effort.

Thus, it is clear that it is not only financial and operational performance that is negatively impacted by poorly managed integration efforts. When the integration is poorly managed, severe and potentially long-lasting damage is done to the relationships between the firm and its employees. The obvious solution is to avoid harming employer/employee relationships in the first place by planning for and conducting M\&A integration efforts well before the damage is done. This need has been addressed in both the academic and practitioner literature (e.g., Knilans, 2009; Sherman, 2009; Galpin and Herndon, 2007; LaJoux, 2006; Moyer, 2004). Despite the apparent need, almost half (49\%) of the respondents to a survey of 124 executives and managers from 21 different industries regarding the current state of M\&A integration indicated that their company is in need of "merger repair" (Galpin \& Herndon, 2007).

\section{Defining "Merger Repair"}

The existing research on mergers and acquisitions has focused on deal performance (Agrawal \& Jaffe, 2000; LaJoux \& Weston, 1998; Marks \& Mirvis, 2001) or merger integration (Datta, 1991; Galpin \&Herndon, 2007; Knilans, 2009; LaJoux, 2006; Moyer, 2004; Larsson \& Finkelstein, 1999; Pablo, 1994; Sherman, 2009). There is very limited literature available on how to repair employer/employee relationships once the damage of poor integration has been done. The scarce literature that does exist on merger repair is essentially practitioner oriented (Galpin \& Herndon, 2007). In view of the nascent depth of the topic, an opportunity exists to establish an empirically based conceptual framework for repairing employer/employee relationships resulting from integration missteps. Such a framework will serve to advance both the theoretical understanding of and pragmatic approaches to merger repair.

A potentially useful set of literature for understanding the damaged relationships that often occur in mergers and acquisitions comes from research in social psychology that has focused on the various aspects of damaged relationships. This stream of research includes investigations of violations of trust and the dynamics of distrust (Elangovan \& Shapiro, 1998; Lewicki, McAllister, \& Bies, 1998; Robinson, 1996; Sitkin \& Roth, 1993; Zaheer, Lofstrom, \& George, 2002), breaches of psychological contracts (Morrison \& Robinson, 1997; Robinson \& Rousseau, 1994), negative relations (Labianca, Brass, \& Gray, 1998), feelings of injustice (e.g., Barclay, Skarlicki, \& Pugh, 2005), and revenge (Bies \& Tripp, 1996). This research has primarily focused on the processes by which relationships are damaged, as opposed to how relationships are repaired. In an effort to address this deficiency Dirks, Lewicki, and Zaheer (2009) developed a definition of 
relationship repair: "Relationship repair occurs when a transgression causes the positive state that constitutes the relationship to disappear and/or negative states to arise, as perceived by one or both parties, and activities by one or both parties substantively return the relationship to a positive state" (p. 69).

This definition is pertinent to the issues involved in repairing the damage that accrues when integration transgressions occur in mergers and acquisitions. In this context, the "parties" of the relationship are the senior management team of an entity undertaking a merger or acquisition and the combined workforce of the new entity. The definition offered by Dirks et al. identifies a potentially equal share of responsibility among each of the parties within a relationship for "relationship repair." Applying the definition to the context of a "merger repair" requires modification because most, if not all, of the weight of responsibility for both the "transgressions" and the necessary "repair" falls on the senior management team of the newly combined organization. This is an essential amendment of the definition because the senior management team has much greater control over the actions that can create the transgressions during the integration effort. The level of responsibility for the needed relationship repair is symmetrical to the level of control over the offending actions. Not only does the senior management team have the power to potentially prevent these transgressions, they have the power to take the actions necessary to repair these breaches of confidence and trust. Moreover, it should be noted that some mergers and acquisitions are resisted by employees from the very beginning, before any integration actions have occurred. Thus, integration transgressions may further damage an already poor management/employee relationship. Therefore, we propose the following definition of merger repair: Merger repair occurs when an integration transgression (or series of integration transgressions) by senior management damages the existing state that constitutes the relationship between the management team of the newly combined organization and its employees, as perceived by one or both parties, and activities by senior management substantively return the relationship to a more positive state.

A clear example of both an antecedent and consequence of transgressions in management behavior during mergers and acquisitions is employee trust. A model of trust presented by Mayer, Davis, \& Schoorman (1995) defines trust as "the willingness of a party [employees] to be vulnerable to the actions of another party [management] based on the expectation that the other will perform a particular action important to the trustor [employees], irrespective of the ability to monitor or control that other party [management]" (1995, pg 712). Mayer, et al. propose that in a relationship with another party (e.g. management), trust is based on employee perceptions of three characteristics of management -ability, benevolence, and integrity. Perceived ability is the extent to which management is deemed to possess the skills and competencies in the area of interest, giving management the capacity to contribute to the employees' well-being. Perceived benevolence is the extent to which management is believed to desire to do positive things for the employees. Perceived integrity means that the party adheres to a set of values that employees' find acceptable. Mayer et al. propose that 
the decline and repair of these three dimensions lead to changes in the level of trust itself.

An important dimension of Mayer et al.'s model is a feedback loop from the outcome of risk taking behavior on the part of management back to the three trustworthiness factors. Mayer, et al. use the feedback loop to purport that, after taking a risk, management will observe outcomes regarding the trust relationship. If the outcomes are positive, prior employee trust in management will be reinforced, and trust will either be maintained or incrementally strengthened. If the outcomes are negative, some combination of management's ability, benevolence, and integrity will be reevaluated by employees and possibly scaled back, leading to a lowered level of trust. Consequently, the feedback loop accounts for the evolution of trust over time and for abrupt changes in trust after significant negative outcomes.

Therefore, trust can be repaired by increasing the trustworthiness dimension - ability, benevolence, and integrity - that declined. These dimensions of trust are significant for merger repair in that they imply what management needs to do to "repair" the employer/employee trust relationship, with each of the three dimensions - ability, benevolence, and integrity - having clear implications regarding the particular issues employees are concerned about and what management might do to address and repair those issues. The actions that management can take to repair trust and other key domains of the employer/employee relationship are addressed in more detail later in our discussion.

\section{Three Domains of Merger Repair}

The relationship repair literature identifies three primary factors that are consistently impacted during transgressions and that have significant consequences for the viability of relationships: trust, affect, and exchange (Dirks et al., 2009). When trust is damaged due to a relationship transgression or series of transgressions, people form inferences about future behaviors of the transgressor, negative expectations replace positive expectations, and individuals become unwilling to expose themselves to further vulnerability (Lewicki, McAllister, \& Bies, 1998). Similarly, workforce trust can be damaged when integration transgressions occur in poorly conducted merger and acquisition integration efforts (Maguire \& Nelson, 2008; Searle \& Kirstie, 2004). The specific causes of damaged employee trust during these organizational combinations can take many forms. It is common for the management team to make statements such as, "There will be no layoffs due to this merger." But, within a short time after that declaration, management announces layoffs. Management can also make a proclamation such as, "We will move quickly to combine the two companies once the deal is closed." Subsequently, several years pass before any integration changes actually occur. Yet another breach of trust can be management's claim during the announcement of a deal that they will communicate frequently with employees about integration, but then do not provide any communication for months afterward. 
These common communication-based transgressions, although they may not be intentional, often result in the creation of psychological contracts between the management team and the employees (Robinson, 1996). These psychological contracts are sets of implicit expectations formed by employees based on what they heard and understood. When the "promised" outcomes fail to materialize, employees experience a breach of trust. Because of the implicit nature of the contract that was breached, these violations are particularly difficult for management to deal with. The management team was likely unaware of the existence of the contract, yet they are now held liable for the violation. For these reasons, we expect that

Proposition 1: Employee trust will be negatively correlated with the presence of management transgressions during merger integration.

The second factor impacted by relationship transgressions is affect, manifested in the form of negative emotions such as disappointment, frustration, and anger (Barclay et al., 2005; Conway \& Briner, 2002; Bies \& Trip, 1996). As Dirks et al. (2009) point out, "Negative affect (e.g. general dislike, feelings of injustice) has important implications for the viability of the relationship...because one party may terminate the relationship to avoid the negative state" (p. 70). Negative employee affect has been found to result from poorly conducted mergers (Klendauer \& Deller, 2009). This may result in the unwanted turnover of key talent (Kiessling, Harvey, \& Heames, 2008; Kummer, 2008). During merger integrations, negative employee emotions can be created when management communicates one message, but takes actions that are contradictory to their communicated messages. Likewise, negative affect can be caused by management taking too long to make integration decisions, leaving the workforce wondering about such things as the security of their jobs, as well as the compensation and benefit plans that will be used in the newly combined organization. Therefore, we expect

Proposition 2: Employee affect will be negatively impacted by the presence of management transgressions during merger integration.

Beyond the drop in trust and the creation of negative affect, the third factor impacted by relationship transgressions is exchange. In general relationships are guided by a norm of reciprocity (Blau, 1964). As relationships grow and improve, this generalized reciprocity becomes the norm, which is "characterized by indefiniteness in the obligation ... (that) reflects a kind of altruistic interest in others" (Sparrowe \& Liden, 1997, p. 524). Unlike trust, reciprocity does not involve optimistic expectations for an outcome (Golembiewski \& McConkie, 1975). It does, however, suggest prescribed behavior to stabilize exchange when harm is encountered (Becker, 1986). Reciprocity as an expectation of behavior dealing with response to harm, should distinguish itself from trust, which reflects a belief in the ability, benevolence, and integrity of another (Mayer, et al., 1995), and therefore have an independent effect on commitment. However, it is also likely that trust will become stronger as both parties to an exchange consistently and productively respond to problems (Pervan, Bove, \& Johnson, 2009). Despite the norm of reciprocity, individuals who perceive they are mistreated in a relationship tend to suspend positive exchange. Thus, normal levels of organizational citizenship behaviors such as cooperation, collaboration, and team work diminish. Furthermore, 
following a relationship transgression, cooperation not only drops but, if repair actions are not pursued cooperation can continue to drop until it actually ceases to exist (Bottom, Gibson, Daniels, \& Murningham, 2002). In more extreme responses, employees may engage in negative exchange behaviors such as reprisals, withheld effort, and revenge (Bottom et al., 2002; Nakayachi \& Watabe, 2005; Ren \& Gray, 2009; Schweitzer, Hershey, \& Bradlow, 2006; Tomlinson, Dineen, \& Lewicki, 2004;).

These negative exchange behaviors have been shown to be created in situations of poorly conducted organizational integrations (Klendauer \& Deller, 2009; Piske, 2002; Wall, 2001). The implications of negative exchange during organizational integration efforts are substantial and can impair the likelihood of the merger or acquisition ever achieving the intended outcomes. Thus, we expect

Proposition 3: Employee exchange behavior will be negatively impacted by management transgressions during merger integration.

Trust, affect, and exchange behavior are interdependent attitudes and behaviors. Thus, it is imperative that all three factors be addressed during merger repair. Addressing each of these will improve the employer/employee relationships in the short run. This also creates a solid foundation for the long term success of the integration effort. Addressing simply one of the factors during merger repair may help to ameliorate a portion the damaged relationships created from poorly executed integration. However, to have the broadest and longest lasting impact on repairing damaged relationships all three factors should be addressed. While positive exchange may be restored, the lack of trust and high negative affect may still exist. Thus, it is important to embrace a broad definition of merger repair. Although this may not be an issue in the short term, the overlooked factor may eventually undermine the relationship in the long term. For instance, after an integration transgression occurs (e.g. management declaring no job losses due to the merger, but announcing layoffs shortly thereafter) employees may still be compelled to collaborate with management on implementing integration actions for fear of losing their jobs. In this situation, management's actions may have damaged two key dimensions of trust; i.e. employee perceptions of management's benevolence and/or integrity (Mayer et al., 1995). However, employees may exhibit continuance commitment - remaining because they have no options - but, not have any sense of affective commitment to the organization (Meyer \& Allen, 1991).

\section{Integrity is More Important than Competence}

Relationship transgressions can be categorized into two types - integrity and competence (Tranfinow, Bromgard, Finlay, \& Ketelaar, 2005; Kim, Ferrin, Cooper, \& Dirks, 2004; Sitkin \& Roth, 1993). In their review of the literature on the construct, Bews and Rossouw (2002) defined integrity as "the application of a set of moral and ethical principles, acceptable to both trustor and trustee, which are predictable and reliable" ( $p$. 382). This definition, as applied to the employee/employer relationship, suggests that management's integrity is determined by the set of moral and ethical principles they demonstrate to employees with predictability and reliability throughout the M\&A process. 
In addition to integrity, several studies have focused on the role of competence in the trust relationship (Brocker \& Siegel 1996; Mishra 1996; Robbins, 1997), with competence being defined as "the trustor's perception that the trustee possesses the technical and interpersonal skills required for a job" (Kim et al., 2004, p. 106). This definition indicates that, during M\&As, both technical and interpersonal skills play a key role in shaping employees' perceptions.

While both integrity and competence play a role in the employer/employee relationship throughout mergers and acquisitions, transgressions of integrity appear to possess more severe consequences than a lack of competence. First, transgressions of integrity create more negative emotions than those of competence (Tranfinow et al., 2005). Second, transgressions of integrity seem to have a halo effect and these transgressions may influence attributions concerning other aspects of the relationship (Sitkin \& Roth, 1993). For example, when integrity is violated people may be more likely to perceive the transgressor to lack competence as well. This could be due to the slighted party's (e.g. employees') assumption - rightly or wrongly - that competent management would not violate integrity. Alternatively, it might be that integrity violations by management are perceived by employees as being intentional. Violations of competence can be viewed by employees as occurring due to a lack of M\&A skill, knowledge or experience on the part of management. As Sitkin \& Roth (1993) identify, competence and integrity may be correlated, however, further empirical research is needed to more fully explore the relationship between these two factors.

Because transgressions of integrity create more negative emotions and seem to spill over into attributions of competence, managers should do everything they can to avoid integrity transgressions during organizational integration efforts. Employees may forgive management for transgressions of competence, such as not possessing the project management skills that are required to manage a complex integration effort. However, they will find it much harder to overlook violations of trust such as financial misstatements or going back on promises made in earlier communications. In short, a management team that commits transgressions of integrity will have to work much harder at merger repair. If the integrity violations are severe enough, the only solution may be to bring in a new management team that has a "clean slate" in order to help repair the damaged employer/employee relationship. Unfortunately, the breach of trust created by a previous management team may linger into the new team's tenure. Thus, we expect that

Proposition 4: Management transgressions of integrity will have a more significant impact on employee trust, affect, and exchange than transgressions of competence during merger integration.

\section{A Conceptual Framework for Merger Repair}

Integrating the existing research on relationship transgression and repair in combination with the existing research regarding organizational integration, we offer a five-stage framework of "merger repair". We have included key questions corresponding to each 
stage of the model, as guidance to both management and researchers regarding the type of information needed to identify: the pre-deal state of the employer/employee relationship; the integration transgressions committed; the impact of those transgressions on the employer/employee relationship; the management actions that can be taken to repair the damaged relationship; and the effects of those repair actions. The five stages in the model are:

1) Pre-Transaction - What is the current state of employer/employee trust, affect, and exchange?

2) Integration Transgressions - What transgressions have been committed (integrity and/or competence)?

3) Damaged Relationship - Which employer/employee factors (trust, affect, and exchange) have been impacted and to what extent?

4) Merger Repair - What actions can be taken to repair the damaged factors?

5) Post-Repair Assessment - What is the state of trust, affect, and exchange after the repair actions are taken?

Figure 1

Conceptual Framework for Merger Repair

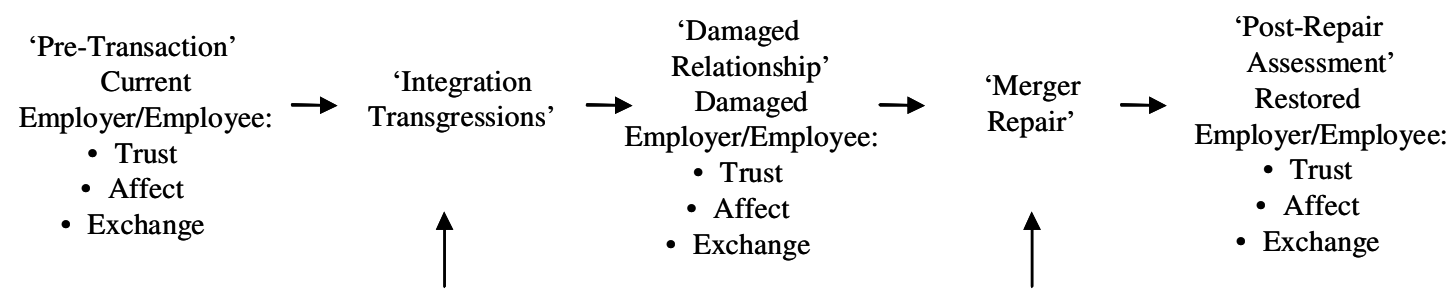

$$
\begin{aligned}
& \text { Example Transgressions: } \\
& \text {-Limited communication } \\
& \text {-False statements } \\
& \text {-Slow decision making } \\
& \text {-Inadequately addressing } \\
& \text { organizational cultural } \\
& \text { differences } \\
& \text {-Little or no focus on } \\
& \text { retaining key talent } \\
& \text {-Not having a clear } \\
& \text { integration management } \\
& \text { approach } \\
& \text {-Implementing } \\
& \text { operational and } \\
& \text { organizational changes } \\
& \text { too slowly }
\end{aligned}
$$

Example Repair Actions:
-Frequent communication
-Correcting false
statements
-Faster decision making
-Cultural integration
- Key talent retention
-Integration project
management rigor
-Accelerate operational
and organizational
changes
-Replace NewCo
management (specific
individuals or entire
team)

Example Repair Actions: -Frequent communication - Correcting false statements -Faster decision making -Cultural integration -Key talent retention -Integration project and organizational changes

-Replace NewCo management (specific individ
team)

During stage one - pre-transaction - management can rapidly obtain an understanding of the current levels of trust, affect, and exchange that exist among the employees of both organizations involved in the transaction before the transaction is completed. This information can quickly be collected through online surveys and/or by interviewing a sample of employees from each organization. The data can be used to compare the pre-deal perceptions of the combining companies' workforces about their trust levels in management (e.g. integrity, fairness, reliability); their emotions toward the company (e.g. enthusiasm, optimism, confidence); and their levels of exchange (e.g. cooperation, 
effort, collaboration) between themselves and the company. A survey of this kind would be an important addition to due diligence efforts that normally emphasize only the financial and legal aspects of the proposed merger. These data can then serve as a baseline for future measurement regarding the impact of integration efforts on employee trust, affect, and exchange.

Beyond data collection relating to the three relationship factors, pre-transaction is the stage during which management can focus their integration planning efforts on preventing transgressions in order to avoid the need to take merger repair actions. They can do this by ensuring that integration actions are well planned and well executed - for example that: communication is honest and frequent, integration is measured and results are regularly reported, actions to retain key employees are planned and implemented, and integration decisions are clear and communicated (Galpin \& Herndon, 2007; Goulet \& Schweiger, 2006; LaJoux, 2006; Marks \& Mirvis, 1998). Therefore, we expect

Proposition 5: Trust, affect, and exchange will be positively impacted by the presence of a well planned and executed set of merger integration actions.

The second stage of the model - integration transgressions - is characterized by the occurrence of one or more management transgressions during integration. It should be noted that many deals die before they are completed (due to the buyer and/or seller pulling out). Consequently, many transactions never reach the integration implementation stage. However, integration planning often begins prior to actual deal close and therefore integration transgressions can occur before a deal is closed and even if it ultimately doesn't go through. These transgressions can include, but are not limited to management: delaying the start of the integration planning effort until after the deal closes; failing to assign appropriate integration resources early and not keeping them available throughout the integration effort; not clearly defining performance expectations and/or integration strategy; failing to develop and execute detailed integration plans; not implementing regular deal performance measurement, tracking, and reporting; neglecting to make and/or communicate key decisions in a timely and coordinated manner; communicating one thing (e.g. announcing that certain locations will remain in tact), but ultimately doing another (e.g. closing those locations shortly thereafter) (Carleton \& Lineberry, 2004; Galpin \& Herndon, 2007; Hanson, 2001; Schweiger, 2006). Committing any of these integration transgressions can destroy trust, create disappointment and frustration, and lower levels of effort and collaboration among the newly created organization's employees, customers, and shareholders. Thus, we expect

Proposition 6: Employer/employee relationship factors (trust, affect, and exchange) will be negatively impacted by the presence of merger integration transgressions.

The transgressions committed in stage two of the model bring about the third stage of the model - damaged relationship. At this stage, management should determine which employer/employee factors (trust, affect, and exchange) have been impacted and to what extent they have been damaged. As in the pre-transaction stage, this assessment 
can quickly be completed through online surveys and/or by interviewing a sample of employees. The data collected can be used to compare the pre-deal perceptions of the combining companies' workforces regarding their trust in management; their affect toward the newly created organization; and their levels of exchange between themselves and the company. This data then serves as a catalyst to initiate the next stage of the model - merger repair.

Once integration transgressions occur and the employer/employee relationship is damaged, merger repair is required. The actions required of management during this stage are ultimately what will determine if the three employee relationship factors - trust, affect, and exchange - are returned to, or at least brought back closer to pre-deal levels. In order to avoid further deterioration of the relationship between management and employees, merger repair actions should be implemented quickly and decisively., These efforts should include: focusing on measurable results improvement in strategically important areas such as sales or production, setting clear improvement goals (e.g. clearly identifying what must be accomplished and by when); establishing very short timeframes for improvement (e.g. weeks or months, rather than years); assigning direct personal accountability to individual members of management for each repair action; coordinating repair activities through detailed project plans; putting in place additional integration resources and/or changing personnel assigned to integration activities; retracting and/or clarifying misstatements made by management about the integration effort; dismissing members of management who have committed egregious transgressions during the integration process (Galpin \& Herndon, 2007; Schaffer \& Ashkenas, 2005). Thus, we expect

Proposition 7: Employer/employee relationship factors (trust, affect, and exchange) will be positively impacted by a well executed set of merger repair actions.

The final stage - post-repair assessment - is the stage during which management can determine to what extent the merger repair actions have been successful. Post-repair measurement can be compared with the levels of pre-deal trust, affect, and exchange of the organization's employees. This evaluation will provide management with key data to ascertain whether or not they should: 1) conclude their merger repair actions because they have succeeded in improving the three relationship factors among employees, or 2) implement additional and/or different repair actions because they have not yet improved employee trust, affect, and exchange.

\section{Summary}

In this paper we have presented a comprehensive framework of merger repair. Our model extends the relationship repair work of Dirks et al. (2009) who noted that, "Relationship repair is a fundamental, but surprisingly under studied problem" (p. 82). Similarly, whereas merger integration has been studied extensively, we found that even though merger repair is a frequent occurrence in practice it remains an entirely unaddressed area of intellectual inquiry. We believe our model has implications for both organizational scholars and management practitioners. 


\section{Implications for Research}

The model we have presented identifies several implications for scholars investigating the subject of merger repair as recognized in our seven propositions. The propositions we have developed need to be tested empirically. In order to do so, the construct of merger integration best practices must first be validated, as numerous integration actions exist that are currently regarded as "best practice" (Schweiger \& Goulet, 2000). Once this has been clarified, future research should then examine the specific propositions we have identified. These include further research into: the relationship between merger integration transgressions and employee trust, affect, and exchange; the relative impact on employer/employee relationships of management integrity transgressions as opposed to transgressions of competence during merger integration; and the relationship between merger repair actions and employee trust, affect, and exchange.

The ideal approach to investigating the propositions offered in our model would be to do a longitudinal study in the form of a quasi field experiment utilizing both qualitative observations and quantitative assessment of employee attitudes. This would require enough advance notice of a pending combination of two organizations to do an assessment of pre-acquisition employee attitudes. Researchers would need to have access to employees before the potential deal was made public. In fact, access would be required early in the internal communication phase of a proposed merger. This requirement is a major limitation to being able to fully test the propositions we have developed.

The integration effort would need to be monitored to identify specific incidents of integration transgressions and the impact of these transgressions on employees would need to be documented. This would then set the stage for the intervention of merger repair activities. Finally, the post-repair attitudes of the employees could be assessed to determine the effectiveness of the repair effort.

While this approach would be ideal, it would be extremely difficult to implement for several reasons. The advance notice of a pending merger or acquisition would be hard to obtain due to the secrecy that usually surrounds these strategic maneuvers. This is further complicated by the need to assess employee attitudes in both organizations prior to the announcement of the pending action. Management teams may be reluctant to allow this type of access. Moreover, as is the case with all longitudinal field studies, the problem of attrition will hinder any empirical analysis. This problem will be particularly acute in this situation because right-sizing and layoffs are normally associated with post-merger activities.

These difficulties should not deter efforts to examine integration transgressions and merger repair activities empirically. However, such efforts may be confined to crosssectional approaches that will make it difficult to provide the pre-test/post-test assessment of the effectiveness of the proposed merger repair interventions. 


\section{Implications for Practice}

The propositions developed in this paper are not only intended to guide future research in this area, but they are offered as principles to guide managers as they prepare for and move through a merger integration process. Thus, the model presented in this paper has important implications for practicing managers and organizational consultants. First, our model suggests that management can prevent the need for merger repair by conducting M\&A integration properly through a set of well planned and executed integration actions. Management teams must be intentional about conducting per-merger assessments that take into account the complexity of organizations. Management philosophy, organizational processes, human resource practices, and organizational cultures cannot be ignored during the due diligence phase of pre-merger activities.

Although our model and the propositions we developed were framed so that they would guide future research, we believe this work also provides a useful diagnostic framework for managers and consultants working with organizations in transition. The questions that accompany each phase of the model can guide inquiry that leads to a greater understanding of the underlying issues. The research propositions may be interpreted as prescriptions for practice, both in the prevention of transgressions and the repair of breaches in trust. As such the model will assist managers in anticipating potential problems, developing thorough integration plans, and executing those plans in an effort to avoid the transitional problems we have identified.

Our model also suggests that employer/employee relationships can be severely damaged if integration is not done correctly. Thus, we believe it is important that those conducting mergers and acquisitions be trained in merger integration best practices. Moreover, management must be able to rapidly assess the status of the employer/employee relationship throughout the merger integration process. Finally, managers should also understand how to quickly apply merger repair actions when required.

We have framed our analysis in the context of the issues and challenges faced by managers attempting to integrate organizations during M\&A efforts. While our discussion has focused on this particular phenomenon, we believe that the transgressions identified can also occur in the context of any organizational change effort. Thus, the prescriptions developed here for preventing transgressions and repairing them when they do occur can be generalized to other organizational change

efforts including: organizational restructuring, company downsizing, major process redesign, strategy implementation, and culture change. In fact, many of the transgressions and breaches of trust discussed in this paper occur in organizations everyday - independent of merger activity. Managers who are more aware of these transgressions will be equipped to avoid them, or repair damaged relationships when they occur. Managers who do so will enhance their employees' trust and commitment. 


\section{References}

Agrawal, A., \& Jaffe, J. F. (2000). The post-merger performance puzzle. In C. Cooper \& A. Gregory (Eds.), Advances in Mergers and Acquisitions (pp. 7-42). New York: JAI Press.

Atkinson, P., \& Clarke, D. (2007). Due diligence. Management Services, 51, 9-13.

Banerjee, A. V. (1992). A simple model of herd behavior. Quarterly Journal of Economics, 107, 797-817.

Barclay, L., Skarlicki, D. P., \& Pugh, S. D. (2005). Exploring the role of emotions in injustice perceptions and retaliation. Journal of Applied Psychology, 90, 629-643.

Becker, L. C. (1986). Reciprocity. New York: Routledge and Kegan Paul.

Bedeian, A., \& Armenakis, A. (1998). The Cesspool Syndrome: How dreck floats to the top of declining organizations The Academy of Management Executive, 12(1), 58-67.

Bews, N. F., \& Rossouw, G. J. (2002). A role for business ethics in facilitating trustworthiness. Journal of Business Ethics, 39, 377-390.

Bies, R.J., \& Tripp, T.M. (1996). Beyond distrust: Getting even and the need for revenge. In R. Kramer, \& T. Tyler, (Eds.), Trust in organizations: Frontiers of theory and research (pp. 246-260). Thousand Oaks, CA: Sage.

Blau, P. (1964). Exchange and power in social life. New York: Wiley.

Bottom, W. P., Gibson, K., Daniels, S., \& Murningham, J. K. (2002). When talk is not cheap: Substantive penance and expressions of intent in rebuilding cooperation. Organization Science, 13, 497-513.

Brahma, S. S., \& Kailash B. L. (2007). Communication, executive retention, and employee stress as predictors of acquisition performance: An empirical evidence." ICFAI Journal of Mergers \& Acquisitions, 4, 7-26.

Brocker, J., \& Siegel, P. (1996). 'Understanding the interaction between procedural and distributive justice: The role of trust. In R. M. Kramer \& T. R. Tyler (Eds.), Trust in Organizations: Frontiers of theory and research (pp. 390-413). Thousand Oaks, CA: Sage.

Bruner, R. (2005). Deals from Hell - M\&A lessons that rise above the ashes. New York: Wiley.

Burt, R. S. (1992). Getting ahead. Structural holes: the social structure of competition. Cambridge, MA: Harvard University Press.

Calandro Jr., J. (2008). Assessing the risk of M\&A: Bruner's Disaster Framework applied to Berkshire Hathaway's Gen Re Acquisition. Strategy \& Leadership, 36, 20-27.

Cameron, K., Quinn, R., Degraff, J., \& Thakor, A. (2006). Competing values leadership: Creating value in organizations. Northampton, MA: Edward Elgar.

Carow, K., Heron, R., \& Saxton, T. (2004). Do Early Birds Get the Returns? An empirical investigation of early-mover advantages in acquisitions. Strategic Management Journal, 25, 563-585.

Carleton, J. R., \& Lineberry, C. (2004). Achieving post-merger success: A stakeholder's guide to cultural due diligence, assessment, and integration. San Francisco: Pfeiffer. 
Conway, N., \& Briner, R. B. (2002). A daily diary study of affective responses to psychological contract breach and exceeded promises. Journal of Organizational Behavior, 23, 287-302.

Cyert, R. M., \& March, J. M. (1963). A behavioral theory of the firm. Englewood Cliffs, CA: Prentice-Hall.

Datta, D. K. (1991). Organizational fit and acquisition performance: Effects of postacquisition integration. Strategic Management Journal, 12, 281-297.

Dirks, K. T., Lewicki, R. J., \& Zaheer, A. (2009). Repairing relationships within and between organizations: Building a conceptual foundation. Academy of Management Review, 34, 68-84.

Edmondson, G., Welch, D., Thornton, E., \& Palmer, A. (2005). Dark days at Daimler. BusinessWeek online. Retrieved October 7, 2009, from http://www.businessweek.com/magazine/content/05_33/b3947001_mz001.htm

Elangovan, A. R., \& Shapiro, D. L. (1998). Betrayal of trust in organizations. Academy of Management Review, 23, 547-566.

Fisher, J. T. (2004). M\&A integration at Delta Connection Inc: The importance of employee and company culture in a corporate transaction. The Journal of Risk Finance, 5, 14-17.

Galpin, T., \& Herndon, M. (2007). The complete guide to mergers and acquisitions: Process tools to support integration at every level ( $2^{\text {nd }}$ ed.). San Francisco: Jossey-Bass.

Gilbert, N. (1989). The M\&A cradle game for young companies on the fast track. Management Review, 78, 14.

Golembiewski, R. T., \& McConkie, M. (1975). The centrality of interpersonal trust in group processes. In C. L. Cooper (Ed.), Theories of Group Processes (pp. 131185). New York: Wiley.

Goulet, P. K., \& Schweiger, D.M. (2006). Managing culture and human resources in mergers and acquisitions. In G. Stahl \& I. Bjorkman, (Eds.), Handbook of research in international human resource management (pp. 405-432). Northampton, MA: Edward Elgar.

Guerrera, F. (2009). Flawed conception. Financial Times.com. Retrieved October 7, 2009, from http://www.ft.com/cms/s/0/5f7295e8-e437-11dd-82740000779fd2ac.html

Haleblian, J., Devers, C. E., McNamara, G., Carpenter, M.A., \& Davison, R.B. (2009). Taking stock of what we know about mergers and acquisitions: A review and research agenda. Journal of Management, 35, 469-502.

Hanson, P. (2001). The m\&a transition guide: A ten-step roadmap for workforce integration. New York: John-Wiley.

Hunter, K. G. (2002). An application of herd theory to interest group behavior. Administration \& Society, 34, 389-410.

Ibrahim, M. (2009). Theory of bounded rationality. Public Management, 91, 3-5. Janis, I. L. (1982). Victims of groupthink (2nd ed.). Boston: Houghton Mifflin.

Joyce, E. (2003). Time Warner nixes AOL from nameplate. ClickZNews. Retrieved October 7, 2009, from http://www.clickz.com/showPage.html?page=3079621 
Kim, P. H., Ferrin, D. L., Cooper, C. D., \& Dirks, K. T. (2004). Removing the shadow of suspicion: The effects of apology vs. denial for repairing ability- vs. integritybased trust violations. Journal of Applied Psychology, 89, 104-118.

Klendauer, R., \& Deller, J. (2009). Organizational justice and managerial commitment in corporate mergers. Journal of Managerial Psychology, 24, 29-45.

Knilans, G. (2009). Mergers and acquisitions: Best practices for successful integration. Employment Relations Today, 35, 39-46.

Kiessling, T., Harvey, M., \& Heames, J. T. (2008). Acquisition issues: Operational changes to the acquired firm's top management team and subsequent organizational performance. Journal of Leadership \& Organizational Studies, 14, 287-302.

Kummer, C. (2008). Motivation and retention of key people in mergers and acquisitions. Strategic HR Review, 7, 5-10.

Labianca, G., Brass, D. J., \& Gray, B. (1998). Social networks and perceptions of intergroup conflict: The role of negative relationships and third parties. Academy of Management Journal, 41, 55-67.

Lajoux, A. R. (2006). The art of m\&a integration: A guide to merging resources, processes, and responsibilities ( $2^{\text {nd }}$ ed.). New York: McGraw-Hill.

Lajoux, A. R., \& Weston, J. F. (1998). Do deals deliver post-merger performance? Mergers and Acquisitions, 33, 34-37.

Larson. R., \& Finkelstein, S. (1999). Integrating strategic, organizational, and human resource perspectives on mergers and acquisitions: A case survey of synergy realization. Organization Science, 10, 1-26.

Lewicki, R. J., McAllister, D. J., \& Bies, R. J. (1998). Trust and distrust: New relationships and realities. Academy of Management Review, 23, 438-458.

Maguire, S., \& Nelson, P. (2008). 'Citibankers' at Citigroup: A study of the loss of institutional trust after a merger. Journal of Management Studies, 45, 372-401.

Marley, M. (2008). A strong case for and against monster deals. American Metal Market, 117, 38.

Marks, M.L. (1999). Adding cultural fit to your diligence checklist. Mergers and Acquisitions, 34, 14-20.

Marks, M. L., \& Mirvis, P. H. (2001). Making mergers and acquisitions work. Academy of Management Executive, 15, 80-94.

Marks, M. L., \& Mirvis, P. H. (1998). Joining forces: Making one plus one equal three in mergers, acquisitions, and alliances. San Francisco: Jossey-Bass.

Mayer, R., Davis, J., \& Schoorman, F. (1995). An integrative model of organizational trust. Academy of Management Review, 20, 709-734.

Meyer, J., \& Allen, N. (1991). The three-component conceptualization of organizational commitment. Human Resource Management Review, 1, 61-89.

Michener, H. S., \& DeLameter, J. D. (1999). Theoretical perspectives in social psychology. Fort Worth, TX: Harcourt Brace College Publishers.

Mishra, A. K. (1996). Organizational responses to crisis. The centrality of trust. In R. M. Kramer \& T. R. Tyler (Eds.), Trust in organizations: Frontiers of theory and research (pp. 261-287). Thousand Oaks, CA: Sage. 
Morrison, E. W., \& Robinson, S. L. (1997). When employees feel betrayed: A model of how psychological contract violation develops. Academy of Management Review, 22, 226-256.

Moyer, D. (2004). The sin in synergy. Harvard Business Review, 82, 131.

Nakayachi, K., \& Watabe, M. (2005). Restoring trustworthiness after adverse events: The signaling effects of voluntary "hostage posting" on trust. Organizational Behavior and Human Decision Processes, 97, 1-17.

Nofsinger, J. R., \& Sias, R. W. (1999). Herding and feedback trading by institutional and individual investors. Journal of Finance, 54, 2263-2295.

Pablo, A. L. (1994). Determinants of acquisition integration level: A decision-making perspective. Academy of Management Journal, 37, 803-836.

Pervan, S., Bove, L., \& Johnson, L. (2009). Reciprocity as a key stabilizing norm of interpersonal marketing relationships: Scale development and validation. Industrial Marketing Management, 38, 60-70.

Pfeffer, J., \& Salancik, G. R. (1978). The external control of organizations. New York: Harper \& Row.

Piske, R. (2002). German acquisitions in Poland: An empirical study on integration management and integration success. Human Resource Development International, 5, 295-312.

Prince, T. (2009). Hits and misses. Journal of Commerce, 10, 40.

Ren, H., \& Gray, B. (2009). Repair relationship conflict: How violation types and culture influence the effectiveness of restoration rituals. Academy of Management Review, 34, 105-126.

Robbins, S. P. (1997). Essentials of organizational behavior ( $5^{\text {th }}$ ed.). Upper Saddle River, NJ: Prentice-Hall.

Robinson, S. L. (1996). Trust and breach of the psychological contract. Administrative Science Quarterly, 41, 574-599.

Robinson, S. L., \& Rousseau, D. M. (1994). Violating the psychological contract: Not the exception but the norm. Journal of Organizational Behavior, 15, 245-259.

Schaffer, R.H., \& Ashkenas, R. (2005). Rapid results! How 100-day projects build the capacity for large scale change. San Francisco: Jossey-Bass.

Scharfstein, D. S., \& Stein, J. C. (1990). Herd behavior and investment. American Economic Review, 60, 465-479.

Schweiger, D. M. (2006). M\&A integration: A framework for executives and managers. New York: McGraw-Hill.

Schweiger, D. M., \& DeNisi, A. S. (1991). Communication with employees following a merger: A longitudinal field experiment. Academy of Management Journal, 34, 110-135.

Schweiger, D. M., \& Goulet, P. K. (2000). Integrating mergers and acquisitions: An international research review, in C. Cooper \& A. Gregory, (Eds.), Advances in Mergers and Acquisitions, (pp. 61-91). New York: JAI Press.

Schweitzer, M. E., Hershey, J. C., \& Bradlow, E. T. (2006). Promises and lies: Restoring violated trust. Organizational Behavior and Human Decision Processes, 101, 119.

Searle, R. H., \& Kirstie S. B. (2004). The development of trust and distrust in a merger. Journal of Managerial Psychology, 19, 708-721. 
Sherman, A. J. (2009). Managing the postclosing integration. Journal of Corporate Accounting \& Finance, 20, 17-23.

Sitkin, S. B., \& Roth, N. L. (1993). Explaining the limited effectiveness of legalistic "remedies" for trust/distrust. Organization Science, 4, 367-392.

Skinner, B. F. (1953). Science and human behavior. New York: Macmillan.

Sparrowe, R. T., \& Liden, R. C. (1997). Process and structure in leader-member exchange. Academy of Management Review, 22, 522-552.

Taylor, P. (2006). Sprint Nextel replaces operating chief. Financial Times.com. Retrieved August 22, 2006, from http://www.ft.com/cms/s/33404e74-31fc-11dbab06-0000779e2340.html

Tomlinson, E. C., Dineen, B. R., \& Lewicki, R. J. (2004). The road to reconciliation: Antecedents of victim willingness to reconcile following a broken promise. Journal of Management, 30, 165-187.

Tranfinow, D., Bromgard, I. K., Finlay, K. A., \& Ketelaar, T. (2005). The role of affect in determining the attributional weight of immoral behaviors. Academy of Management Review, 34, 85-104.

Ulrich, D., Cody, T., LaFasto F., \& Rucci, T. (1989). Human resource at Baxter Healthcare Corporation merger: A strategic partner role. Human Resource Planning, 12, 87-103.

Wall, S. J. (2001). Making mergers work. Financial Executive, 17, 34-67.

Zaheer, A., Lofstrom, S., \& George, V. (2002). Interpersonal and organizational trust in alliances. In F. Contractor \& P. Lorange (Eds.), Cooperative strategies and alliances: What we know 15 years later (pp. 347-377). London: Elsevier Science. 